\title{
EQUITY MARKETS RISKS AND RETURNS: IMPLICATIONS FOR GLOBAL PORTFOLIO CAPITAL FLOWS DURING PANDEMIC AND CRISIS PERIODS
}

\author{
Pavlo Dziuba', Olena Pryiatelchuk², Denys Rusak ${ }^{3}$
}

\begin{abstract}
The paper is devoted to the study of risk and return tradeoff in the global equity market as well as particular market groups: developed, emerging and frontier markets. Impact of this tradeoff on international equity portfolio liabilities is explored. The study confirms the hypothesis that there are some specific patterns of risk and return tradeoff during crisis periods and periods of markets regular regime that substantially differ from each other and define global portfolio equity flows and liabilities in a specific way. The paper thus carries out its main objective that implies revealing these patterns with respective qualitative features and quantitative markers, specifying their implications for equity portfolio flows to markets of different types. Risks and returns for different market groups and global market as a whole are calculated for the period between 2002 and 2020 using standard methodology of contemporary portfolio theory and $\mathrm{MSCl}$ indices monthly values. The data for international equity portfolio liabilities as well as the share of particular market group in the global market are used as dependent variables. The latter are regressed by calculated risks and returns. Using the model results and some analytical developments, two patterns of risk/return tradeoff are discovered. The pattern attributable to regular market regimes is characterized by positive returns which is $1.51 \%$ in average for the global market, $1.48 \%$ for developed markets and $2.03 \%$ for emerging markets. Risks in regular pattern are relatively small or moderate at the average level of 3.05 for the global market and are all below the median (3.48). Respective risks for developed and emerging markets are 3.02 and 4.54. The Sharpe ratios in regular pattern are positive at the average level of 0.60 for the global market, 0.57 and 0.45 for developed and emerging market groups respectively. The crisis pattern implies negative returns at the mean of -1.04 for the global market, -0.97 for the developed group and -1.35 for the emerging markets. High risks are all above the median and in average compile 5.5 for the global market, 5.47 for the developed markets and 6.68 for the emerging group. Sharpe ratios for this pattern are negative being equal to -0.19 in the mean. The average value is -0.18 for developed markets and it is -0.24 for emerging markets. Specific pattern of 2020 crisis should be settled out. Its main feature that substantially distinguishes it from other crises is the combination of highest risk level and the positive returns at the same time. Elaborated regression model confirms the direct impact of return and indirect impact of risk on global portfolio liabilities. The influence of risk for regular and crisis patterns does not differ substantially while the impact of return is much stronger during periods of increased volatility (respective model parameters are 3793.76 and 447.24). However, the discovered impact is much more reliable in crisis pattern that is supported by much higher determination ratio. Developed markets experience similar effects.
\end{abstract}

Key words: international (equity) portfolio liabilities, risk, return, risk/return tradeoff, increased volatility, developed markets, emerging markets, frontier markets, COVID crisis.

JEL Classification: F21, F37, G11, G15, C46

\footnotetext{
Corresponding author:

${ }^{1}$ Taras Shevchenko National University of Kyiv, Ukraine.

E-mail: pavlo.dziuba@gmail.com

ORCID: https://orcid.org/0000-0003-2932-0908

${ }^{2}$ Taras Shevchenko National University of Kyiv, Ukraine.

E-mail: pryyatelchuk@gmail.com

ORCID: https://orcid.org/0000-0002-5222-452X

ResearcherID: I-1126-2018

${ }^{3}$ Taras Shevchenko National University of Kyiv, Ukraine.

E-mail: derusak@ukr.net

ORCID: https://orcid.org/0000-0001-6603-0761
} 


\section{Introduction}

Global portfolio capital flows have traditionally proved themselves to be very sensitive to different fluctuations in international financial markets, to specific shocks and turmoil in the global economy, as well as to particular unexpected shifts in business environment. Unlike foreign direct investments they rapidly respond to all mentioned changes and can be quickly shifted from one market to another, providing, on the one hand, markets liquidity and on the other hand, international capital movement. Therefore, portfolio flows represent the most mobile element of global capital flows. At the same time such flows result from particular decisions of particular international investors that in turn ground on three basic factors of portfolio decision making: risk, return and investor's risk tolerance. In the present study we are not going to consider such higher order investment moments skewness and kurtosis as well as interrelation between returns under question since they would rather require specific attention in a stand-alone research. Good theoretical analysis and empirical insights of this issue based on contemporary data and particular cases are provided by Kim et al. (2014), Mei et al. (2017), Rogach, Shnyrkov \& Dziuba (2019) and others.

Thus, our main focus will lie on risk and return in different markets and market groups, their dynamics and particular changes during periods of instability especially during current pandemic.

As it is known, interrelation between returns is considered to be one of the basic preconditions for increasing efficiency of investment portfolios via decreasing their risks. Notwithstanding this interrelation is extremely important in terms of contemporary portfolio theory insight and from empirical viewpoint it is derivative or so to say secondary considering its origin among other investment data. It is derived using the primary data on returns and somehow even the data on risks. Therefore, the primary investment decisionmaking factors concentrate in risk-return framework with returns covariance remaining a supplementary index.

Another point of the special attention is the contemporary pandemic. One could hardly find any field not affected by the COVID-19 pandemic during the last couple of years. The case is specifically challenging for the global economy that felt the pandemic influence substantially. That is also the point of an extreme importance for international financial markets that experienced significant volatility in 2020 and experience quite different expectations at the beginning of 2021 . That resulted in substantial volatility of global market capitalization, increased volatility of returns in individual markets, decrease of international portfolio flows. This point is also to be studied in our research. One of our challenging expectations is that there might be a specific pattern of risk / return tradeoff that differs for periods of increased instability and for period of markets regular regime. One of these differences could be the shift of portfolio decisions between developed and less developed markets. Such patterns could be used to explain and somehow to forecast international portfolio flows. Moreover, one of the probable results of this study might be the comparison of mentioned patterns between different turmoil periods. The impact of crises of different types could be also different.

\section{Literature review}

Contemporary theory of portfolio investing substantially rests on a well-known Markowitz theory or as it is more often referred to as portfolio theory. One of its most profound provisions tells us that investment decisions are made by portfolio investors considering risk and return, and that statement is equally true to both investment portfolios and individual securities (Markowitz, 1952, 1959). These two investment indices are reciprocal meaning the higher risk investors accept the higher risk premium they require. This point is the direct result of investors' rationality and risk aversion behavior. Interrelations between individual securities returns should also be considered while composing a portfolio: the lower they are the more efficient portfolio can be built up. These ideas have set up a dominating paradigm in the field which was joined and expanded by other approaches and concepts, such as resulting from fundamental seminal studies of Sharpe (1964), Lintner (1965), Black (1972), Merton (1973), Black \& Litterman (1992) and others as well as findings of some more recent research like Jobson (1991), Best \& Grauer (1991), Jorion (1992), Arnott \& Bernstein (2002), Lehar (2005) etc.

Analysis of risks and returns of international markets is considered to have been originated in the framework of international diversification concept founded by Grubel (1968) and Solnik (1974). This concept substantially rests on traditional portfolio theory, making it actually universal in terms of domestic and international markets exploration. Its main focus is on risks, returns and interrelation between returns that is considered to be the main prerequisite for portfolio efficiency increase. This in turn stems from Markowitz portfolio risk formula incorporating covariance between returns. Mathematically the latter should be as low as possible. Unlike studies of domestic markets research of internationally diversified portfolios mostly consider risks, returns and interrelation between returns for individual markets rather than individual securities. This is sort of extrapolation where an individual security under traditional approach is replaced by the whole market of a particular country in international diversification concept. 
Grubel (1968) for example considers investment portfolios in two countries with only three possible investment alternatives (forms of holding wealth): real assets, money and bonds. After being autarchical mutual ownership of bonds is possible after opening these economies. Real estate and money sections of local portfolios remain unchanged. Main conclusions of Markowitz theory were generally supported but Grubel stressed out the importance of international investing in bonds. Addressing only five factors of investing in foreign bonds Grubel concluded that only if they remained the same demand for foreign bonds would be equal in both countries and both portfolios would be identical. Empirical test using 11 developed markets from the US investor viewpoint proved that international diversification allowed to reach much better risk/return tradeoff while such markets as Japan, the UK and Australia seemed to be the most attractive.

Findings on more than 300 stocks from 7 European and US market using their weekly returns between 1966 and 1971 are provided by Solnik (1974). This study has become the seminal paper in the field. Particular number of portfolios consisting of a given quantity of stocks (from 1 to 300) was randomly composed. Standard deviations for each portfolio were calculated and analyzed. Solnik generally confirmed already existing idea about the minimum non-diversifiable level of risk that could not be removed away but at the same time he proved that this level was much lower for internationally diversified portfolio than for domestic market portfolios. This particular level of relative risk was $11.7 \%$ for international market portfolio compared to $27 \%$ for the US market. Another significant idea was also confirmed: marginal diversification effect was decreasing with the expansion of portfolio structure. These results are explained by the fact that returns in different markets typically have lower correlations than returns of average stocks from the same market. That is because different markets have different systematic and specific factors affecting returns, mismatching between economic and business cycles etc. Additional efficiency of international portfolio can be reached via combining purely international (by markets) and industry diversification. The effect of industry diversification was heavily studied in more recent papers with generally positive conclusions like in Cavaglia, Brightman \& Aked (2000), Moerman (2008), Donadelli \& Paradiso (2014), Zaremba \& Umutlu (2018), Bai \& Green (2020) and others.

Besides the mentioned studies further research in the field proactively explored risks and returns of different markets trying to discover implications for international diversification of investment portfolios. Different markets risks, returns and their correlations particularly in terms of their sustainability were studied by Longin \& Solnik (1995). Using monthly excess returns for seven countries between 1960 and 1990 they found out that covariance and correlation matrices between them were not stable over time. However, they discovered the increase of correlation over 30 years and what is particularly relevant in terms of the present study that correlations increased during periods of increased volatility, i.e., during crises and turmoil. These findings promote further research particularly regarding changes of risk/return profile during different time periods. Karolyi \& Stulz (1996) showed that comovements between different markets stock returns strongly depended on the absolute level of market return, particularly using the example of Japanese stock market and S\&P index. The higher the absolute return of a market in a pair the higher the correlation. They also confirmed the point about high correlations during periods of high volatility. That diminishes the advantages of international diversification during turmoil periods especially considering that large shocks spread more internationally than the small shocks. Bekaert et al. (1998) traditionally supported the generally higher level of volatility in emerging equity markets focusing on the fact that additional measures like skewness and kurtosis should be used for asset allocation. In emerging markets returns distributions are far from being normal compared to developed markets.

Increase of correlations between markets returns during bear regimes but not during bull regimes was proved by Longin \& Solnik (2001) using the monthly data for the five largest stock markets for the 38-year period. Similar idea was also supported by Ang \& Bekaert (2002), who underlined that those correlations decrease in highly volatile periods might question benefits of international diversification of investment portfolios from the U.S. investor perspective. However, they finally fix that international diversification is still valuable under regime shifts particularly when currency hedging opportunities are engaged. The substantial and powerful background for these and similar results stems from the idea that benefits and advantages of international diversification are exaggerated, particularly provided in a long-lasting debate by Lessard (1976), Butler and Joaquin (2002) and others. In addition to the mentioned studies there is a great pile of scientific literature exploring different markets, their risks and returns considering different regions, or specific countries, or particular crisis periods such as Morana \& Beltratti (2002), Niklewski \& Rodgers (2013), Dziuba (2017), Yakubovskiy, Rodionova \& Kyfak (2019) etc.

Hossein \& Nossman (2011) studied the spillover of risk to European equity markets depending on the risk source: US market, regional market and idiosyncratic shocks during the period between 1982 and 2007. They proved that the impact of the US market was generally lower than that one of local markets though it remained substantial for all local markets. In terms of risk management these results stand for good benefit for American investors when they invest during crisis 
periods. Using the G7 markets case, Androkopoulos, Angelidis \& Skintzi (2014) explore the spillover of risk, return and illiquidity. They discover the existence of strong contemporaneous dependence between illiquidity and return within each market with return casing illiquidity. The opposite is not true in most cases. Relation between illiquidity and volatility is significant within US market only. Wang \& Khan (2017) find out that risk-returns tradeoff is time-varying depending on the market states for the US as well as for international market. Aslanidis, Christiansen \& Savva (2016) utilize the set of five large European stock markets (France, Germany, Italy, Switzerland and the UK) and explore the intertemporal risk-return relation. Keeping for three groups of factors (country specific, Euro area and global) they reveal that there is a strong negative relation between conditional return and conditional volatility. The optimal combination of influencing factors varies across the markets. Umantsiv et al. (2019) explored among others efficiency of managing public enterprises in terms of risks of their shares. There is a good portion of research devoted to markets of different types and regions, particularly carried out by Rogach \& Dziuba (2017), they explored risks and returns for frontier markets group considering exchange rate risk factor, and Cheng \& Jahan-Parvar (2014) studied risks and returns in equity markets of Pacific Basin countries etc.

\section{Hypothesis, methodology and data}

Risk and return tradeoff and the importance of this factor in terms of global capital flows define the framework, rationale and coherence of our study. Our primary hypothesis provides that there are some specific patterns of risk and return tradeoff during crisis periods (for developed, emerging and frontier markets as well as for the global market as a whole) that substantially differ from those ones relevant for regular markets regimes and that define global portfolio equity flows in such periods. In the light of confirming or rejecting this hypothesis the main objective of the present study appears to reveal these patterns with respective quantitative markers, define their essential differences from patterns of regular market regimes and to specify their implications for equity portfolio flows to different market groups.

Risks and returns will be explored using standard technique. Morgan Stanley Capital International indices monthly data for different market groups will be analyzed (MSCI, 2021). All indices' values are at a gross level and converted into USD. Absolute values are used to compute returns and their standard deviations. Developed market group is represented by 24 markets: Canada, the USA, Austria, Belgium, Denmark, Finland, France, Germany, Ireland, Israel, Italy, the Netherlands, Norway, Portugal, Spain, Sweden, Switzerland, the UK, Australia, Hong Kong, New Zeeland, Japan and
Singapore. Consolidated analysis of the group will be carried out using the special MSCI World Index (World). Emerging markets include Argentina, Brazil, Chile, Colombia, Mexico, Peru, Czech Republic, Egypt, Greece, Hungary, Kuwait, Poland, Qatar, Russia, Saudi Arabia, South Africa, Turkey, United Arab Emirates, China, India, Indonesia, Korea, Malaysia, Pakistan, the Philippines, Taiwan and Thailand-27 marketsaltogether. Respective group index is the MSCI Emerging Markets Index (EM). Finally, the frontier group is represented by 22 markets of Croatia, Estonia, Lithuania, Kazakhstan, Romania, Serbia, Slovenia, Kenya, Mauritius, Morocco, Nigeria, Tunisia, Benin, Senegal, Ivory Coast, Burkina Faso, Bahrain, Jordan, Oman, Bangladesh, Sri Lanka and Vietnam. This group is generalized by the MSCI Frontier Markets Index (FM). All markets representing MSCI standalone indices are excluded from the study. For the global market we shall use the MSCI All Countries World Index + Frontier Markets (ACWI FM). All data cover the period between June 2002 and December 2020 (March 2021 where available). The latter date is quite reasonable since it reflects the latest available full year data. The first date is explained by the fact that the IMF data on global portfolio assets and liabilities is provided since 2001 and later on in the present study we shall use this data. Thus, we fix the beginning of the period under question by 2002 since the earlier analysis would be of much less use in terms of contemporary crises. The full MSCI data for all indices used is available since May 2002 only. Where possible, we shall also address the data for 2021 though it is not reflecting the full year and thus should be treated with caution.

Market groups volatility will be estimated using monthly returns computed via the standard statistical approach. Standard deviations will be calculated for 12 monthly returns for each year under question. Such approach might seem to be statistically inconsistent due to the little quantity of observations - all others equal 60 returns is considered to be relevant quantity. However, since the expected statistical result is quite predictable considering existing factors and actually known periods of instability, we do not need the precise statistical coincidence and other possible statistical verification. The pure quantitative result would be quite sufficient for the current analysis. Exceptions are for 2002 where we have only 7 returns and for 2021 with 3 returns only.

Data on global portfolio flows is represented by assets and liabilities figures rather that by direct flows data. That is because of two reasons. Firstly, cumulative data is much more sustainable in terms of statistical analysis compared to the yearly basis data. Secondly, the IMF Coordinated Portfolio Investment Survey (CPIS) provides assets and liabilities statistics in a comprehensive and organized way so that it can be relevantly used in the analysis (IMF, 2021-1). This data 
will be arranged for all countries represented by MSCI indices mentioned above reflecting assets and liabilities in equity securities (installments in investment fund securities are also included) at each year end.

Global market capitalization data stand for all domestic markets cap and is provided by the World Federation of Exchanges - WFE (WFE, 2021). It is also the stockage data as of the end of the year. The data for 2021 is as of the end February - the latest available data.

Identifying crisis periods can be carried out using purely equity market markers. They might be global market capitalization; global portfolio equity flows and world market volatility measured as a traditional standard deviation. The first indicator is obviously the derivative from the second and the third, since the decrease in capitalization is typically the direct results of rapid increase in volatility and equity outflows particularly the shift from equities to debt securities. So, we can actually exclude this indicator as the secondary one and use it rather to check the obtained results than to get them. Interrelation between flows and volatility is not so evident; it can be either direct or reverse. All in all, volatility is the pure characteristic of the market, the primary reflection of the underlying processes, interaction between demand and supply. Therefore, we shall use this ratio to define periods of increased volatility in the global market and utilize two other indicators as auxiliary ones.

Another approach could be logical or dialectical when we just identify the instability period using the wellknown facts and considering existing environmental factors. We shall consider the mentioned points just to confirm the identified downturns and help explaining one or another market behavior. The matter is that existing factors are normative in their essence, they just show what should be or how the market should behave. However, we really do not know what is actually going on in the markets. Considering this we should use some market indicator like volatility or others.

\section{Main findings}

Identification of increased volatility periods

Dynamics of global market volatility expressed as ACWI FM index standard deviation is presented at Figure 1 and demonstrates that during the period under question we can fix four well-defined periods of volatility jump: 2007-2008, 2015, 2018 and 2020.

Firstly, the period $2007-2008$ is the most obvious one. It was the global financial crisis. Notwithstanding the major crisis drop down happened in 2008 it also touched upon two months of 2007 and still the volatility began increasing slightly before the crisis itself. So, regardless the nominal increase of volatility in 2007 we shall consider this period as 2008 only. Furthermore, the 2007 volatility increase was pretty small and can be considered as current market adjustment. For this period volatility increase is explicitly supported by predicted substantial drop in world market capitalization as well as by decrease of global portfolio assets in equity.

Secondly, volatility increase in 2015 accounts for such major factor as stagnation in world economy

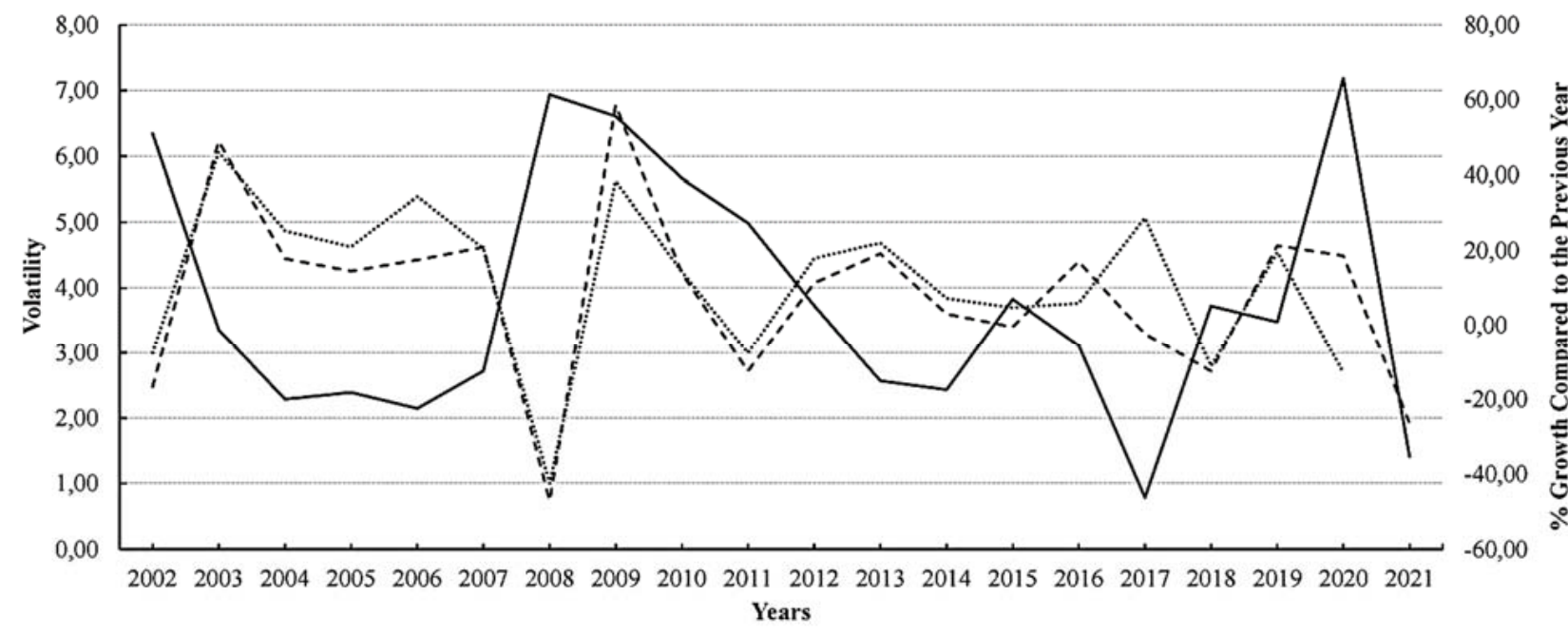

Figure 1. Dynamic of global market volatility, global market capitalization and global portfolio assets in equity Notes:

1. Respective figures are computed and the graphs are composed by the authors using the data on global equity market capitalization (WFE, 2021), global portfolio assets in equity (IMF, 2021-1) and data on indices (MSCI, 2021).

2. For the purposes of simplification and facilitating results perception underlying calculations are not provided.

3. Volatility data is reflected on the primary (left) axis, capitalization and assets data is lain off on secondary (right) axis.

4. For better visualization capitalization and assets are expressed as percentage changes as to the previous year. 
accompanied by the global GDP decline by more than $5.5 \%$. Some of the basic underlying factors were the decrease in oil prices, low inflation and respective central banks measures, China financial crisis including renminbi depreciation and high unemployment in Europe. Global market cap and world portfolio liabilities also responded to these fundamentals as well as during the previous period.

Third, the 2018 volatility rise is also backed by decrease of global equity market cap and global portfolio assets. Basic reasons for this are the slowdown of industrial production and world trade that resulted from introduction of tariffs by major countries in the aftermath of trade tensions between main global players. This in turn brought about the sharp decrease of general business confidence and increase of uncertainty about trade policy and investment decisions. One substantial factor for this period was the USD appreciation that resulted in a so-called emerging market sell-off. That was because the general level of dollar measured return decreased thus reducing the level of risk investors were ready to bear via investing in emerging markets.

Finally, the most up-to-date COVID crisis falls at 2020 mostly. For this year, we observe the highest absolute level of volatility 7.19 (6.94 in 2008). Global portfolio assets dropped by $12.96 \%$ while the capitalization generally increased but the rate fell from 21.30 in 2019 to 18.52 in 2020 . It however responded heavily in 2021 - falling by $26.53 \%$.

Moreover, there are three specific years that do not fall under the present analysis directly. The year 2021 is not represented by the complete statistics set thus we can regard it as the crisis year only verbally. The 2011 demonstrated the decrease of global cap as well as global equity liabilities though it did not show the increase in volatility as such. However, volatility absolute level was 4.99 that was high enough to identify it as substantial. Negative events in 2011 were mostly connected with European debt crisis together with the decrease in the US credit rating and earthquake in Japan. Table 1 also shows that in 2011 returns were negative for all market groups which was typical for crisis periods. Considering this we shall include this year to the increased volatility set. The very similar case is for 2002. We can thus identify our criteria as follows: increased volatility period is defined as such when the volatility is higher that the median (3.48) except for the cases when volatility has decreased compared to the previous year. This formal criterion completely meets verbal description of the crisis periods observed.

Basic considerations for volatility increase in 2002 are connected with three main factors. Firstly, the terrorist attacks in the USA hit a blow to the global economy in general. As a result, expectations of major market participants regarding the world economy restoration in 2002 remained weak. Secondly, the number of foregoing financial scandals negatively influenced financial markets and added weakness to general expectations regarding the global economy restoration and corporate governance. One well known scandal was connected with Enron multinational giant and Arthur Andersen consulting company. Third, some momentum in financial markets still remained after the "dot.com" crises.

Results of risk and return calculation using the abovementioned methodology are presented in Table 1.

There might be several ways how to identify the risk / return pattern. Herein we are going to utilize the standard methodology implying computation of a so-called risk-adjusted return using the traditional Sharpe ratio. The latter is just the relation of risk premium (difference between return and risk-free rate) to standard deviation. Having risks and returns we shall thereto utilize the average for annual returns of the US treasury bills that is traditionally used as a risk-free rate of return. Respective calculations appear in Table 2.

\section{Model specification}

In order to prove the stated hypothesis right or wrong we are going to model the impact of risk and return on foreign portfolio assets and liabilities for specific market groups. For this purpose, we shall construct a regression model with risk and return being independent variables and portfolio assets / liabilities being dependent variable. Actually, we are going to explore two groups of models. First group implies analyzing liabilities as dependent variable during periods of increased volatility. We are considering foreign portfolio liabilities for the global market as well as for three particular market groups during years of increased volatility that will be analyzed altogether. Liabilities will be regarded in terms of their absolute values as well as shares (shares of equity liabilities of particular market group in the total figure of equity liabilities). This data is presented in Table 3.

Thus de facto we shall construct and study 7 models in the first group since every mentioned case will be individually treated for dependent variable measured in absolute figures ( 4 models) and measured as a percentage ( 3 models). For the latter percentages are not relevant. Second group implies the same "duplicated" dependent variable but for periods of regular volatility level 7 models altogether again. We are not going to study assets for a quite simple reason: risk and return are pull but not push factors of portfolio investments implying that only liabilities matter.

As for the percentage shares of different market groups we consider this piece of data to be substantial since crisis period impacts not only absolute investment level but the relative attractiveness of different markets uppermost. The analysis like this might be even more meaningful than the traditional approach with absolute values. 
Vol. 7 No. 3, 2021

Table 1

Dynamics of Risks and Returns for the Global Market and Particular Market Groups,

T-bill Average Annual Return (2002 - 2021)

\begin{tabular}{|c|c|c|c|c|c|c|c|c|c|c|c|}
\hline Year & ACWI FM & World & EM & $\mathrm{FM}$ & $r_{f}$ & Year & $\begin{array}{c}\text { ACWI } \\
\text { FM }\end{array}$ & World & EM & $\mathrm{FM}$ & $r_{f}$ \\
\hline \multirow{2}{*}{2002} & -2.39 & -2.46 & -2.04 & 1.59 & \multirow{2}{*}{1.61} & \multirow{2}{*}{2012} & 1.37 & 1.35 & 1.58 & 0.77 & \multirow{2}{*}{0.09} \\
\hline & 6.34 & 6.47 & 6.59 & 2.94 & & & 3.73 & 3.56 & 5.43 & 2.34 & \\
\hline \multirow{2}{*}{2003} & 2.50 & 2.51 & 3.88 & 3.11 & \multirow{2}{*}{1.01} & \multirow{2}{*}{2013} & 1.80 & 2.07 & -0.14 & 2.02 & \multirow{2}{*}{0.06} \\
\hline & 3.36 & 3.41 & 4.18 & 3.14 & & & 2.57 & 2.55 & 3.26 & 3.36 & \\
\hline \multirow{2}{*}{2004} & 1.24 & 1.21 & 2.04 & 1.75 & \multirow{2}{*}{1.37} & \multirow{2}{*}{2014} & 0.42 & 0.48 & -0.08 & 0.64 & \multirow{2}{*}{0.04} \\
\hline & 2.28 & 2.25 & 4.33 & 2.67 & & & 2.43 & 2.36 & 3.76 & 3.52 & \\
\hline \multirow{2}{*}{2005} & 0.94 & 0.82 & 2.65 & 4.91 & \multirow{2}{*}{3.15} & \multirow{2}{*}{2015} & -0.09 & 0.05 & -1.19 & -1.21 & \multirow{2}{*}{0.05} \\
\hline & 2.39 & 2.27 & 5.42 & 7.27 & & & 3.82 & 3.85 & 4.87 & 3.11 & \\
\hline \multirow{2}{*}{2006} & 1.65 & 1.60 & 2.51 & -0.66 & \multirow{2}{*}{4.72} & \multirow{2}{*}{2016} & 0.73 & 0.70 & 1.04 & 0.31 & \multirow{2}{*}{0.32} \\
\hline & 2.14 & 2.00 & 5.16 & 4.63 & & & 3.11 & 3.05 & 4.92 & 3.02 & \\
\hline \multirow{2}{*}{2007} & 1.01 & 0.80 & 2.96 & 3.01 & \multirow{2}{*}{4.41} & \multirow{2}{*}{2017} & 1.86 & 1.75 & 2.72 & 2.38 & \multirow{2}{*}{0.93} \\
\hline & 2.72 & 2.61 & 5.09 & 2.78 & & & 0.78 & 0.79 & 1.81 & 1.81 & \\
\hline \multirow{2}{*}{2008} & -4.16 & -3.98 & -5.54 & -5.92 & \multirow{2}{*}{1.46} & \multirow{2}{*}{2018} & -0.71 & -0.64 & -1.18 & -1.38 & \multirow{2}{*}{1.94} \\
\hline & 6.94 & 6.59 & 10.36 & 7.99 & & & 3.72 & 3.77 & 4.27 & 3.95 & \\
\hline \multirow{2}{*}{2009} & 2.77 & 2.47 & 5.27 & 1.34 & \multirow{2}{*}{0.16} & \multirow{2}{*}{2019} & 2.09 & 2.16 & 1.55 & 1.43 & \multirow{2}{*}{2.07} \\
\hline & 6.61 & 6.49 & 7.98 & 9.04 & & & 3.48 & 3.39 & 4.55 & 1.93 & \\
\hline \multirow{2}{*}{2010} & 1.20 & 1.13 & 1.64 & 1.94 & 0.13 & 2020 & 1.56 & 1.55 & 1.71 & 0.47 & 0.38 \\
\hline & 5.66 & 5.66 & 5.83 & 4.71 & 0.13 & 2020 & 7.19 & 7.30 & 7.21 & 7.72 & 0.38 \\
\hline 2011 & -0.47 & -0.31 & -1.43 & -1.63 & 006 & 2021 & 1.54 & 1.67 & 0.79 & 0.28 & \\
\hline 2011 & 4.99 & 4.85 & 6.77 & 3.23 & 0.06 & 2021 & 1.40 & 1.89 & 1.87 & 0.11 & \\
\hline
\end{tabular}

Notes:

1. Figures are calculated by the authors using MSCI data on indices (MSCI, 2021).

2. Returns are reported in the upper row for respective year, risks - in the bottom row.

3. Years of increased volatility are filled in with grey.

4. Treasury bills average annual returns are marked as rf (IMF, 2021-2).

Table 2

Dynamics of Sharpe Ratio for Particular Market Groups (2002 - 2021)

\begin{tabular}{|c|c|c|c|c|c|c|c|c|c|}
\hline Year & ACWI FM & World & EM & FM & Year & ACWI FM & World & EM & FM \\
\hline 2002 & -0.40 & -0.40 & -0.33 & 0.50 & 2012 & 0.37 & 0.38 & 0.29 & 0.33 \\
\hline 2003 & 0.72 & 0.71 & 0.91 & 0.96 & 2013 & 0.70 & 0.81 & -0.04 & 0.60 \\
\hline 2004 & 0.49 & 0.49 & 0.44 & 0.61 & 2014 & 0.17 & 0.20 & -0.02 & 0.18 \\
\hline 2005 & 0.28 & 0.25 & 0.44 & 0.64 & 2015 & -0.02 & 0.01 & -0.25 & -0.39 \\
\hline 2006 & 0.59 & 0.60 & 0.41 & -0.23 & 2016 & 0.23 & 0.22 & 0.21 & 0.09 \\
\hline 2007 & 0.24 & 0.17 & 0.51 & 0.95 & 2017 & 2.29 & 2.12 & 1.46 & 1.27 \\
\hline 2008 & -0.62 & -0.62 & -0.55 & -0.76 & 2018 & -0.23 & -0.21 & -0.31 & -0.39 \\
\hline 2009 & 0.42 & 0.38 & 0.66 & 0.15 & 2019 & 0.55 & 0.59 & 0.30 & 0.65 \\
\hline 2010 & 0.21 & 0.20 & 0.28 & 0.41 & 2020 & 0.21 & 0.21 & 0.23 & 0.06 \\
\hline 2011 & -0.10 & -0.06 & -0.21 & -0.51 & 2021 & 1.10 & 0.88 & 0.42 & 2.55 \\
\hline
\end{tabular}

Note: figures are calculated by the authors using IMF Coordinated Portfolio Investment Survey data (IMF, 2021-1).

Model results

Main results of the constructed model are presented in Table 4. Their general estimation tells us that by and large risk and return impact international portfolio investments in the same direction as basic theories suggest. Most parameters that stand for return positively influence international portfolio liabilities and respective conclusion about risks shows the opposite direction. However, these relations should be analyzed individually for crisis periods and periods of increased volatility.

Periods of regular market regimes demonstrate the reverse impact of risk on international portfolio liabilities. All respective parameters of the model are negative while for developed markets and thus for the world market as a whole the relation is much more substantial compared to other market groups. At the same time the impact of return is either positive 
Table 3

Dynamics of International Portfolio Liabilities for Different Market Groups, bln. USD and \% (2002 - 2020)

\begin{tabular}{|c|c|c|c|c|c|c|c|c|c|}
\hline \multirow{2}{*}{ Year } & \multirow{2}{*}{$\begin{array}{c}\text { Total, bln. } \\
\text { USD }\end{array}$} & \multicolumn{2}{|c|}{ Developed Markets } & \multicolumn{2}{|c}{ Emerging Markets } & \multicolumn{2}{|c|}{$\begin{array}{c}\text { Frontier } \\
\text { Markets }\end{array}$} & \multicolumn{2}{c|}{$\begin{array}{c}\text { Other } \\
\text { Markets }\end{array}$} \\
\cline { 3 - 10 } & & bln. USD & $\%$ & bln. USD & $\%$ & bln. USD & $\%$ & bln. USD & $\%$ \\
\hline 2001 & 5199 & 4130 & 79.44 & 274 & 5.27 & 2.9 & 0.06 & 792 & 15.23 \\
\hline $\mathbf{2 0 0 2}$ & 4808 & 3629 & 75.48 & 270 & 5.61 & 2.7 & 0.06 & 906 & 18.85 \\
\hline $\mathbf{2 0 0 3}$ & 7023 & 5290 & 75.33 & 502 & 7.14 & 4.9 & 0.07 & 1226 & 17.46 \\
\hline $\mathbf{2 0 0 4}$ & 8794 & 6459 & 73.45 & 665 & 7.56 & 8.5 & 0.10 & 1661 & 18.89 \\
\hline $\mathbf{2 0 0 5}$ & 10633 & 7701 & 72.42 & 1010 & 9.50 & 10.9 & 0.10 & 1912 & 17.98 \\
\hline $\mathbf{2 0 0 6}$ & 14284 & 10121 & 70.85 & 1527 & 10.69 & 22.5 & 0.16 & 2614 & 18.30 \\
\hline $\mathbf{2 0 0 7}$ & 17201 & 11361 & 66.05 & 2252 & 13.09 & 37.9 & 0.22 & 3550 & 20.64 \\
\hline $\mathbf{2 0 0 8}$ & 9876 & 6518 & 66.00 & 1079 & 10.92 & 23.6 & 0.24 & 2256 & 22.84 \\
\hline $\mathbf{2 0 0 9}$ & 13669 & 8885 & 65.00 & 1889 & 13.82 & 30.6 & 0.22 & 2866 & 20.96 \\
\hline $\mathbf{2 0 1 0}$ & 15621 & 9942 & 63.65 & 2336 & 14.96 & 38.9 & 0.25 & 3303 & 21.15 \\
\hline $\mathbf{2 0 1 1}$ & 14442 & 9170 & 63.49 & 1894 & 13.11 & 41.1 & 0.28 & 3337 & 23.11 \\
\hline $\mathbf{2 0 1 2}$ & 17028 & 10747 & 63.11 & 2361 & 13.87 & 45.5 & 0.27 & 3874 & 22.75 \\
\hline $\mathbf{2 0 1 3}$ & 20778 & 13805 & 66.44 & 2327 & 11.20 & 50.0 & 0.24 & 4596 & 22.12 \\
\hline $\mathbf{2 0 1 4}$ & 22274 & 14247 & 63.96 & 2486 & 11.16 & 67.1 & 0.30 & 5474 & 24.57 \\
\hline $\mathbf{2 0 1 5}$ & 23330 & 15269 & 65.45 & 2219 & 9.51 & 64.4 & 0.28 & 5778 & 24.77 \\
\hline $\mathbf{2 0 1 6}$ & 24705 & 15854 & 64.17 & 2438 & 9.87 & 65.5 & 0.27 & 6348 & 25.70 \\
\hline $\mathbf{2 0 1 7}$ & 31792 & 20152 & 63.39 & 3358 & 10.56 & 88.3 & 0.28 & 8194 & 25.77 \\
\hline $\mathbf{2 0 1 8}$ & 28253 & 17840 & 63.14 & 2962 & 10.48 & 78.2 & 0.28 & 7373 & 26.10 \\
\hline $\mathbf{2 0 1 9}$ & 33766 & 21612 & 64.00 & 3498 & 10.36 & 90.00 & 0.27 & 8567 & 25.37 \\
\hline $\mathbf{2 0 2 0}$ & 29389 & 18345 & 62.42 & 2820 & 9.59 & 70.2 & 0.24 & 8154 & 27.75 \\
\hline
\end{tabular}

Notes:

1. Figures are calculated by the authors using IMF Coordinated Portfolio Investment Survey data (IMF, 2021-1).

2. Shares for different market groups represent the weight of each group absolute figure in the total volume of equity liabilities.

3. Years of increased volatility are filled in with grey.

4. Data for 2020 is available as of June only.

Table 4

Regression model results

\begin{tabular}{|c|c|c|c|c|c|c|c|}
\hline \multirow{2}{*}{ Market Group } & \multirow{2}{*}{$y$} & \multicolumn{3}{|c|}{ Regular periods } & \multicolumn{3}{c|}{ Increased Volatility } \\
\cline { 2 - 8 } & & $k_{1}$ & $k_{2}$ & $R^{2}$ & $k_{1}$ & $k_{2}$ & $R^{2}$ \\
\hline \multirow{2}{*}{ ACWI FM } & USD & 447.24 & -1463.70 & 6.78 & 3793.76 & -1250.15 & 65.33 \\
\hline \multirow{2}{*}{ World } & USD & 700.19 & -1067.04 & 9.64 & 2393.54 & -825.22 & 67.00 \\
\cline { 2 - 8 } & $\%$ & 1.6397 & -0.8827 & 11.43 & -1.284 & 0.5695 & 33.72 \\
\hline \multirow{2}{*}{ EM } & USD & -194.03 & -71.48 & 14.61 & 227.93 & -97.38 & 41.90 \\
\cline { 2 - 8 } & $\%$ & -0.4799 & 1.0113 & 28.90 & -0.0156 & 0.1460 & 1.85 \\
\hline \multirow{2}{*}{ FM } & USD & -4.6758 & -5.6242 & 26.89 & 1.4493 & 1.7692 & 1.91 \\
\cline { 2 - 8 } & $\%$ & -0.0232 & -0.0073 & 25.12 & -0.0176 & -0.0029 & 24.33 \\
\hline
\end{tabular}

Notes:

1. Figures are calculated by the authors.

2. Model parameters are represented by $\mathrm{k} 1$ and $\mathrm{k} 2$ ratios that respectively stand for return and risk.

(for the global market and for developed markets group) or negative (for emerging and frontier markets). As in the case with risks the significance of this impact is much higher for developed markets than for other market groups. As for the share of a particular market group respective risk parameters are negative for developed markets and positive for emerging markets, while for frontier markets it is actually approaching zero. It means that increase in risk brings about decrease of the share of equity liabilities in developed markets and their increase in emerging markets. This can be explained by the fact that low returns in developed markets are attractive for foreign investors since they imply low risks, and as soon as the latter increase developed markets lose their attractiveness in favor of emerging markets. The case for returns implies positive impact for developed markets and negative for emerging and frontier market groups. To our mind besides purely statistical coincidences such quantitative pattern can be explained by investors subjective perception of risks and returns. Increase 
of returns in developed markets is not accepted by investors as the sign of volatility increase. However, for less developed markets it can be treated as the direct result of increase in risks.

The regular periods pattern can be also described by positive returns in almost all cases with the absolute level for developed markets (and for the global market) being lower than for emerging and frontier markets. There are only three exceptions for frontier markets in 2006, 2009 and 2012 that can be regarded as purely statistical especially considering extremely low level of frontier market capitalization. They in fact do not produce any effect on the global market. Concerning volatility, its description comes from the basic criteria - relatively low levels of risk (below the median) except the cases when the volatility decreases compared to the previous year. Volatility for emerging and frontier markets is in most cases higher compared to developed markets, with some exceptions being for frontier markets only. The Sharpe ratios are all positive for the global market as well as for developed markets. Only few cases of the negative Sharpe ratios can be observed for emerging markets (in 2013 and 2014) and for frontier markets (in 2006).

Periods of increased volatility can be characterized by a specific pattern of risk/return tradeoff. According to the model risk factor also demonstrates reverse impact on portfolio liabilities for the global market and for developed and emerging market groups, while for frontier markets it is direct and pretty small. Return variable influences liabilities directly for all market groups with the impact being much more substantial for developed markets and the global market. Parameters responsible for impact on the shares are all negative and not very substantial.

Absolute returns in crisis periods are mostly negative except for the 2020 only. The last crisis year can be singled out as a separate pattern that essentially differs even from other crisis years. It will be discussed later. There are only two exceptions: frontier markets in 2002 (1.59) and developed markets in 2015 (0.05). These are purely statistical points. All crisis years except 2020 are attributed to the negative Sharpe ratios that are the direct results of negative returns. At the same time, we can say that the higher the volatility the lower the Sharpe ratio.

As for the absolute volume of liabilities it decreases in all crisis years except in 2015. The same behavior is observed for developed markets and frontier markets except in 2011. Emerging markets demonstrated the cut in liabilities in all crisis years. The pattern for other market groups is not so evident, since in some years liabilities increase and in some years they decrease. However, the share of this market group is increasing in all crisis years. That can be explained by the structure of this group. It includes off-shore markets that become more attractive during periods of increased volatility.
Respective share of developed markets does not change substantially but in major years it slightly decreases. The average share for regular period is $67.95 \%$ while for increased volatility it is $66.00 \%$. Respective averages for other market group are $21.21 \%$ and $23.90 \%$ and for emerging markets they are $10.65 \%$ and $9.87 \%$. However, considering much lower investment position level of the two latter groups mentioned changes should be regarded as more substantial compared to developed markets.

Summarizing finally the model reliability in terms of its determination ratio we should note that the model objective is not to confirm the impact of risk and return on international portfolio flows, assets and liabilities. This impact does not raise any doubts. Instead, we would like to identify the relative significance of the impact under question for different market regimes and for different market groups as well as to define particular quantitative estimates of such impact. In terms of existing theory risk and returns are traditional factors of portfolio investing either domestically or internationally. Notwithstanding the model results show that during periods of increased volatility pattern of risk and return impact on portfolio liabilities for the global markets is much more reliable compared to regular periods, respective values of determination ratio are 6.78 and 65.33. The cases for developed and emerging markets are very similar. Only for frontier markets the opposite relation is observed. The impact on particular market group share is less reliable for developed and emerging markets during crises and more reliable during regular periods. For frontier markets respective difference for regular periods is not substantial but for periods of increased volatility the reliability is higher for the share rather than for liabilities themselves.

As we mentioned above the 2020 crisis year can be singled out into a specific pattern that actually does not match main features of the crisis model. That is primarily due to the fact that extremely high levels of risk for all market groups and for the global market positive returns were fixed. In terms of contemporary portfolio theory this fact can seem to be hardly explained. However, to realize the causes of such increase in returns we need to study the structure and stages of the COVID crisis and related events of 2020. Major negative returns in equity markets occurred only in the first quarter of 2020. Even in January and first half of February the global market kept on with little but positive returns despite the COVID pandemic in China. Then the main drop down occurred in the end February and lasted for almost a month. This so-called sell-off was due to the overwhelming panic that started after disease covered Italy. This very period accounts for major portion of high risks in 2020 and the negative returns are estimated on the level more than $-30 \%$ for a month. Then almost half of the year accounted for increase in returns at almost $51 \%$ level. That was due to specific measures 
introduced by governments and central banks as well as to the ease of lockdowns. The second wave of COVID in September and October was not so destructive although is resulted in negative returns at approximate 5-6\% level. The year-end resulted in relatively high positive returns explained by vaccine development and presidential elections in the USA. Major installment in return of the global market is considered to account for the USA equities.

Still such important factors of 2020 as BREXIT and oil crisis require more detailed study. Their impact on equity markets can be also notable, though most researchers agree that the pandemic crisis together with related expectations and effects appeared to be much more substantial and blocked off the influence of other factors. As a result, the precise decomposition of all factors effects for this case is hardly possible.

\section{Conclusions}

We have identified two patterns of risk / return tradeoff that differently impact international equity portfolio liabilities during crisis periods and periods of regular market regimes. Herein we define crisis periods as periods when risk is above the median unless it is not decreasing compared to the previous year. Thus, the more precise term that should be used is periods of increased volatility since we are not inquiring on the crisis type, its depth etc.

The pattern attributable to regular market regimes or regular pattern is characterized by positive returns which is $1.51 \%$ in average for the global market, $1.48 \%$ for the developed markets and $2.03 \%$ for the emerging markets. Frontier markets account for extremely small share in the global capitalization thus being not representative when we talk about any sustainable pattern. Therefore, they are excluded from both patterns features. Risks in regular pattern are relatively small or moderate at the average level of 3.05 for the global market and are all below the median (3.48). Respective risks for developed and emerging markets are 3.02 and 4.54. Sharpe ratios in regular pattern are positive at the average level of 0.60 for the global market, 0.57 and 0.45 for developed and emerging market groups.

The crisis pattern implies negative returns at the mean of -1.04 for the global market, -0.97 for the developed group and -1.35 for the emerging markets. High risks are all above the median and in average compile 5.5 for the global market, 5.47 for the developed markets and 6.68 for the emerging group. The Sharpe ratios for this pattern are negative being equal to -0.19 in the mean. For developed markets the average value is -0.18 and for emerging markets it is -0.24 . What concerns international equity portfolio liabilities they mostly decline during periods of increased volatility in terms of their absolute value: this behavior is typical for the global market as well as for developed and frontier markets. Specific case stands for other markets that could not be analyzed in the full manner since the market data is not available. However, in terms of their liabilities we have defined an important point. The share of this market group always goes up during periods of increased volatility, in some years liabilities increase even in their absolute values. The average share for crisis pattern is $23.9 \%$ while for regular pattern it is only $21.2 \%$. Respective shares of developed and emerging markets slightly decrease.

As for the developed markets our study confirms the idea that risks and returns are lower compared to emerging market group when they are positive (regular pattern), whilst in crisis pattern returns (negative values) in developed markets are not so low. Risks for developed markets are always lower. Generally, most conclusions about developed markets are similar to those regarding the global market since all studied indices are weighted and developed markets account for most their changes resulting from their huge capitalization, being thus very representative for the global market. Considering the Sharpe ratio developed markets demonstrate higher attractiveness for international portfolio investments compared to emerging markets either during crises or in regular periods. Emerging markets perform better in regular pattern and worse in crisis pattern in terms of their return. All in all, they suggest higher level of not only return but risk being more attractive for more risk tolerant investors.

Developed regression model confirms the direct impact of return and indirect impact of risk on global as portfolio liabilities. The influence of risk for regular and crisis patterns does not differ substantially while the impact of return is much stronger during periods of increased volatility (respective model parameters are 3793.76 and 447.24). However, the discovered impact is much more reliable in crisis pattern that is supported by much higher determination ratio. Developed markets experience similar effects. Emerging markets also account for much more reliable effect of risk and return during periods of increased volatility. In regular pattern the impact of return even appears to be reverse though with poor reliability level. However, we should note that statistically the defined impacts can be generally evaluated as not substantial though the model main objective was to discover relative quantitative estimates.

Specific pattern of 2020 crisis should be settled out. Its main feature that substantially distinguishes it from other crises is the combination of the highest risk level and positive returns at the same time. The possible expected outcome of 2020 could be the decrease of returns in equity markets. The COVID factor actually overlapped all other factors affecting risks and returns. Major positive returns resulted from government and central banks measures in most countries and occurred between April and September. 


\section{References:}

Androkopoulos, A., Angelidis, T., \& Skintzi, V. (2014). Illiquidity, Return and Risk in G7 Stock Markets: Interdependencies and Spillovers. International Review of Financial Analysis, 35 (3), 118-127.

Ang, A., \& Bekaert, G. (2002). International Asset Allocation with Regime Shifts. The Review of Financial Studies, 15 (4), 1137-1187.

Arnott, R. D., \& Bernstein, R. L. (2002). What Risk Premium Is Normal? Financial Analysts Journal, 58 (2), 64-85. Aslanidis, N., Christiansen, C., \& Savva, C. (2016). Risk-return Trade-off for European Stock Markets. International Review of Financial Analysis, 46 (3), 84-103.

Bai, Y., \& Green, C. (2020). Country and Industry Factors in Tests of Capital Asset Pricing Models for Partially Integrated Emerging Markets. Economic Modelling, 92 (3), 180-194.

Bekaert, G., Erb, C., Harvey, C., \& Viskanta, T. (1998). Distributional Characteristics of Emerging Market Returns and Asset Allocation. The Journal of Portfolio Management, 24 (3), 102-116.

Best, M. J., \& Grauer, R. R. (1991). On the Sensitivity of Mean-Variance-Efficient Portfolios to Changes in Asset Means: Some Analytical and Computational Results. The Review of Financial Studies, 4 (2), 315-342.

Black, F. S. (1972). Capital Market Equilibrium with Restricted Borrowing. The Journal of Business, 45 (3), $444-455$. Black, F., \& Litterman, R. (1992). Global Portfolio Optimization. Financial Analysts Journal, 48 (5), 28-43.

Butler, K., \& Joaquin, D. (2002). Are the Gains from International Portfolio Diversification exaggerated? The Influence of Downside Risk in Bear Markets. Journal of International Money \& Finance, 21 (7), 981-1011.

Cavaglia, S, Brightman, C., \& Aked, M. (2000). The Increasing Importance of Industry Factors. Financial Analysts Journal, $56(5), 41-54$.

Cheng, A., \& Jahan-Parvar, M. (2014). Risk-Return Trade-Off in the Pacific Basin Equity Markets. Emerging Markets Review, 18 (3), 123-140.

Donadelli, M., \& Paradiso, A. (2014). Is There Heterogeneity in Financial Integration Dynamics? Evidence from Country and Industry Emerging Market Equity Indexes. Journal of International Financial Markets, Institutions and Money, 32 (3), 184-218.

Dziuba, P. (2017). Asymmetry in Risk and Return Fluctuations as a Factor Driving International Portfolio Investments in Crisis Periods. European Cooperation: Scientific Approaches and Applied Technologies, 1 (2), 23-34.

Grubel, H. G. (1968). Internationally Diversified Portfolios: Welfare Gains and Capital Flows. The American Economic Review, 58 (5), 1299-1314.

Hossein, A., \& Nossman, M. (2011). Risk Contagion among International Stock Markets. Journal of International Money \& Finance, 30 (1), 22-38.

IMF (2021). Coordinated Portfolio Investment Survey. International Monetary Fund. Available at: https://data.imf.org/?sk=B981B4E3-4E58-467E-9B90-9DE0C3367363.

IMF (2021). IMF Data. Interest Rates Selected Indicators (T-Bills). International Monetary Fund. Available at: https://data.imf.org/regular.aspx?key=61545855.

Jobson, J. D. (1991). Confidence Regions for the Mean-Variance Efficient Set: An Alternative Approach to Estimation Risk. Review of Quantitative Finance and Accounting, 1 (3), 235-257.

Jorion, P. (1992). Portfolio Optimization in Practice. Financial Analysts Journal, 4 (2), 315-342.

Karolyi, G., \& Stulz, R. (1996). Why Do Markets Move Together? An Investigation of U.S.-Japan Stock Return Comovements. The Journal of Finance, 51 (3), 951-986.

Kim, W., Fabozzi, F., Cheridito, P., \& Fox, C. (2014). Controlling Portfolio Skewness and Kurtosis without Directly Optimizing Third and Fourth Moments. Economic Letters, 122 (2), 154-158.

Lehar, A. (2005). Measuring Systemic Risk: A Risk Management Approach. Journal of Banking \& Finance, 29 (10), 2577-2603.

Lessard, D. (1976). World, Country and Industry Relationships in Equity Returns: Implications for Risk Reduction through International Diversification. Financial Analysts Journal, 32 (3), 32-38.

Lintner, J. V. (1965). The Valuation of Risk Assets and the Selection of Risky Investments in Stock Portfolios and Capital Budgets. The Review of Economics and Statistics, 47 (1), 13-37.

Longin, F., \& Solnik, B. (2001). Extreme Correlations of International Equity Markets. The Journal of Finance, $56(2), 649-676$.

Longin, F., \& Solnik, B. (1995). Is the Correlation in International Equity Returns Constant: 1960-1990? Journal of International Money and Finance, 14 (1), 3-26.

Markowitz, H. M. (1952). Portfolio Selection. The Journal of Finance, 7 (1), 77-91.

Markowitz, H. M. (1959). Portfolio Selection: Efficient Diversification of Investments. New York: John Wiley \& Sons, Inc.; London: Chapman \& Hall, Ltd.; Cowles Foundation for Research in Economics at Yale University.

Mei, D., Liu, J., Ma, F., \& Chen, W. (2017). Forecasting Stock Market Volatility: Do Realized Skewness and Kurtosis Help? Physica A: Statistical Mechanics and Its Applications, 481 (1), 153-159.

Merton, R. C. (1973). An Intertemporal Capital Asset Pricing Model. Econometrica, 41 (5), 867-887. 
Moerman, G. (2008). Diversification in Euro Area Stock Markets: Country versus Industry. Journal of International Money and Finance, 27 (7), 1122-1134.

Morana, C., \& Beltratti, A. (2002). The Effects of the Introduction of the Euro on the Volatility of European Stock Markets. Journal of Banking \& Finance, 26 (10), 2047-2064.

MSCI (2021). MSCI Indexes Performance. End of Day Index Data Search. Morgan Stanley Capital International. Available at: https://www.msci.com/end-of-day-data-search.

Niklewski, J., \& Rodgers, T. (2013). International Portfolio Diversification and the 2007 Financial Crisis. In J. Batten, P. MacKay \& N. Wagner (Eds.), Advances in Financial Risk Management (pp. 225-252). London: Palgrave Macmillan.

Rogach, O. I., \& Dziuba, P. V. (2017). Exchange Rate Risks of International Portfolio Investments: Comparative Analysis of Ukrainian and other Frontier Markets. Transition Studies Review, 24 (1), 31-45.

Rogach, O., Shnyrkov, O., \& Dziuba, P. (2019). Skewness-Based Portfolio Selection: Implications for International Investing in Frontier Markets. Transition Studies Review, 26 (2), 23-38.

Sharpe, W. F. (1972). Capital Asset Prices: A Theory of Market Equilibrium under Conditions of Risk. The Journal of Finance, 19 (3), 425-442.

Solnik, B. H. (1974). Why Not Diversify Internationally Rather than Domestically? Financial Analysts Journal, $30(4), 48-54$.

Umantsiv, I., Lebedeva, L., \& Mytrofanova, A. (2019). Modern Trends in Governance of State Ownership Relations. Baltic Journal of Economic Studies, 5 (5), 155-164. DOI: https://doi.org/10.30525/2256-0742/2019-5-5-155-164 Wang, Z., \& Khan, M. (2017). Market States and the Risk-return Tradeoff. The Quarterly Review of Economics and Finance, 65 (3), 314-327.

WFE (2021). Statistics Portal. World Federation of Exchanges. Available at: https://www.world-exchanges.org/ our-work/statistics.

Yakubovskiy, S., Rodionova, T., \& Kyfak, A. (2019). Inflow of Foreign Capital as a Factor of the Development of Current Accounts of the Eastern European Countries. Transition Studies Review, 26 (2), 3-14.

Zaremba, A., \& Umutlu, M. (2018). Size Matters Everywhere: Decomposing the Small Country and Small Industry Premia. The North American Journal of Economics and Finance, 43 (3), 1-18. 